\title{
Abdominal Compartment Syndrome: A Case Report
}

\author{
Femi Liz Babu1, Teena Thomas', Alisha Maria Shaji ${ }^{2}$ \\ 1PHARM.D (Doctor of Pharmacy) Interns, 2PHARM.D PB Intern \\ 1,2Pushpagiri Medical College Hospital, Thiruvalla, Kerala, India
}

\begin{abstract}
How to cite this paper: Femi Liz Babu | Teena Thomas | Alisha Maria Shaji "Abdominal Compartment Syndrome: A Case Report" Published in International Journal of Trend in Scientific Research and Development (ijtsrd), ISSN: 24566470, Volume-3 I Issue-4, June 2019, pp.660-661, URL: https://www.ijtsrd.c om/papers/ijtsrd23 881.pdf

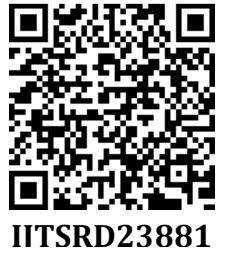

Copyright (C) 2019 by author(s) and International Journal of Trend in Scientific Research and Development Journal. This is an Open Access article distributed under the terms of the Creative Commons

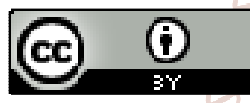
Attribution License (CC BY 4.0) (http://creativecommons.org/licenses/ by $/ 4.0$ )

little is known about the impact of intra-abdominal pressure (IAP) in general internal medicine, pregnant patients, and those with obesity or burns ${ }^{[2]}$. IAH in pregnancy must take into account the precautions for aorto-caval compression and has been associated with ovarian hyper stimulation syndrome.

Three categories of ACS:

$>$ Primary or acute abdominal compartment syndrome occurs when intra-abdominal pathology is directly and proximally responsible for the compartment syndrome

$>$ Secondary abdominal compartment syndrome occurs when no visible intra-abdominal injury is present but injuries outside the abdomen cause fluid accumulation

$>$ Chronic abdominal compartment syndrome occurs in the presence of cirrhosis and ascites or related disease states, often in the later stages of the disease

\section{CASE REPORT}

A 31 year old female patient was admitted under OBG III. ELECTIVE LSCS under SAB on the basis of previous LSCS. Delivered a live term female baby of weight $2.730 \mathrm{~kg}$. APGAR on same day. Family history. Mother - DM on OHA and father is hypertensive patient. The patient is allergic to Rantidine and Cefazolin.

On postoperative day (POD) 2, patient developed severe breathlessness, tachypnoea, tachycardia, facial puffiness, abdominal distension and decreased urine output, hence emergency general medicine consultation was sought in view of the same and their orders were carried out. Emergency UGS abdomen scan taken and the findings are as follows: mild to moderate ascites noted. Patient was shifted to medical icu and was monitored. Next USG abdomen showed moderate hem peritoneum, also the presence of free fluid with internal echoes in sub hepatic, perisplenic regions and in bilateral paracolic gutters as well as in pelvis. Investigation repeated showed severe anemia with fall in $\mathrm{Hb}$. 3 pint PRBS transfusion was done and $\mathrm{Hb}$ was monitored Q6h until stable. Surgery consultation was sought and they gave an impression of abdominal compartment syndrome and $\mathrm{d}$ hence abdominal girth and intra-abdominal pressure was monitored regularly. CVP line was inserted on POD 2. Nephrology consultation was sought for decreased urine output, they gave an impression of transient oliguria. Cardiology consultation was sought to rule out LV dysfunction. ECHO was done and was found to have stable cardiac status. Next USG abdomen : organised echoes are noted in right paracolic gutter extending to the region of umbilicus and also in perisplenic area -could represent organised clots - has reduced compared to previous scan. No free fluid in the abdomen. Gradually, patient improved symptomatically, hence shifted out to ward after removing catheter and CVP line. Patient was noted to have discoloration over the left iliac fossa and left lumbar region which was managed with ichthammol glycerine and chymoral forte. Follow up USG abdomen: hematoma in the perihepatic, perisplenic and periumbilical region shows resolution and approximately measures $390 \mathrm{ccc}$ at present. 
Per operative findings: dense adhesions between the rectus sheath and anterior abdominal wall. Both ovaries and tubes were adherent to the posterior surface of the uterus. Bowel adhesions were present to the posterior surface of uterus.

\section{DISCUSSION}

In the second and the third trimester of pregnancy, the uterus occupies a major part of the abdominal cavity, and in the supine position breathlessness and decreased blood pressure ("supine hypotension syndrome") are often seen ${ }^{[3,4]}$. The expansion of intra-abdominal contents in the form of fluid or tissue is the fundamental cause of increasing IAP leading to the path physiology of IAH and ACS. Pregnancy, with a growing fetus and the increases in intraabdominal fluid and tissue, could be considered a perfect storm for the development of IAH/ACS. Due to baseline increases in IAP, all critically ill obstetrical/gynecologic patients should undergo vigilant IAP monitoring. As intraabdominal pressure rises, progressive organ failure occurs. The kidneys and lungs are the most affected[5]. The mortality rate associated with abdominal compartment syndrome is significant, ranging between $60 \%$ and $70 \%[6,7,8]$

\section{CONCLUSION}

At the cellular level of this syndrome, oxygen delivery is impaired, leading to ischemia and anaerobic metabolism. Vasoactive substances such as histamine and serotonin increase endothelial permeability; further capillary leakage impairs red cell transport; and ischemia worsens. As pressure rises, abdominal compartment syndrome impairs not only visceral organs but also the cardiovascular and the pulmonary systems; it may also cause a decrease in cerebral perfusion pressure. IAP can be easily monitored by measuring bladder pressure. Cheatham et al found abdominal perfusion pressure (APP) to be a much better predictor of end-organ injury than lactate, $\mathrm{pH}$, urine output, or base deficit [9]. Therapy should include fluid resuscitation and transfusion if needed, as well as surgical consultation. A comprehensive, evidence-based approach to the management of abdominal compartment syndrome that includes early use of an open abdomen has been shown to reduce mortality[10]. A group in Taiwan has used laparoscopic decompression successfully in blunt abdominal trauma patients who have an IAP of $25-35 \mathrm{~cm} \mathrm{H}_{2} \mathrm{O}^{[11]}$. The timely diagnosis and appropriate management of ACS in this patient helped her to recover completely.

\section{REFERENCE}

[1] Daniel De Backer. Abdominal compartment syndrome. Crit Care 1999, 3:R103-R104

[2] Anaesthesiology Intensive Therapy 2015, vol. 47, no 3, 228-240 ISSN 0209-1712 10.5603/AIT.a2015.0021

[3] Chun R, Kirkpatrick AW: Intra-abdominal pressure, Intra-abdominal hypertension, and pregnancy: a review. Ann Intensive Care 2012; 2 (Suppl 1): S5. doi 10.1186/2110-5820-2-S1-S5.

[4] Chun R, Baghirzada L, Tiruta C, Kirkpatrick AW: Measurement of Intra-abdominal pressure in term pregnancy: a pilot study. Int J Obstet Anesth 2012; 21: 135-139. doi: 10.1016/j.ijoa.2011.10.010

[5] Aashish Patel1 Chandana G. Lall S. Gregory Jenning. Kumaresan Sandrasegaran AJR. Abdominal Compartment Syndrome:189, November 2007

[6] Meldrum DR, Moore FA, Moore EE, Franciose RJ, Sauaia A, Burch JM. Prospective characterization and selective management of the abdominal compartment syndrome. Am J Surg 1997; 174:667-672

[7]/Tiwari A, Haq AI, Myint F, Hamilton G. Acute compartment syndromes. Br J Surg 2002; 89:397-412 Eddy V, Nunn C, Morris JA Jr. Abdominal compartment syndrome: the Nashville experience. Surg Clin North Am 1997; 77:801-812

[9] Cheatham ML, White MW, Sagraves SG, et al. Abdominal perfusion pressure: a superior parameter in the assessment of intra-abdominal hypertension.J Trauma. 2000 Oct. 49(4):621-6; discussion 626-7.

[10] Cheatham ML, Safcsak K. Is the evolving management of intra-abdominal hypertension and abdominal compartment syndrome improving survival?. Crit Care Med. 2010 Feb. 38(2):402-7.

[11] Chen RJ, Fang JF, Lin BC, Kao JL. Laparoscopic decompression of abdominal compartment syndrome after blunt hepatic trauma.Surg Endosc. 2000 Oct. 14(10):966. 